\title{
Evaluation of coronary calcium score in patients with normocalcemic primary hyperparathyroidism
}

This article was published in the following Dove Press journal:

Vascular Health and Risk Management

22 June 2017

Number of times this article has been viewed

\author{
Patrícia Nunes Mesquita' \\ Ana Paula Dornelas \\ Leão Leite ${ }^{2}$ \\ Stella das Chagas \\ Crisóstomo' \\ Enio Veras Filho' \\ Lucas da Cunha Xavier' \\ Francisco Bandeira'
}

'Unit of Endocrinology, Diabetes and Bone Diseases, Hospital Agamenon Magalhães, ${ }^{2}$ Department of Radiology, University of Pernambuco, Cardiac Emergency Hospital of Pernambuco, Recife, Pernambuco, Brazil
Correspondence: Patrícia Nunes Mesquita Unit of Edocrinology, Diabetes and Bone Diseases, Hospital Agamenon Magalhães, Estrada do Arraial Street, 2723 - Casa Amarela, PE-Recife - PE, 52070-230, Pernambuco,

CEP 52070-020, Brazil

Tel +558I 996736677

Email patymesq@hotmail.com
Rationale: Given that the diagnosis of primary hyperparathyroidism (PHPT) is given at an increasingly less-symptomatic phase, and the literature data on the cardiovascular risk of patients with normocalcemic primary hyperparathyroidism (NPHPT) are controversial, the coronary calcium score (CCS), which is correlated with coronary artery disease, may be useful for clarifying the association between cardiovascular risk and NPHPT.

Objective: This research aims to describe the CCS and the clinical and laboratory variables of patients with NPHPT compared with a control group and to verify the presence of an association between NPHPT and CCS.

Study population and methods: A questionnaire on anthropometric data (weight, height, waist circumference, and blood pressure) was used, laboratory examinations (estimations of glucose, glycated hemoglobin [HbA1c], total cholesterol [TC] and its fractions, triglycerides, creatinine, calcium, parathyroid hormone, and $25-\mathrm{OH}$ vitamin $\mathrm{D}$ ) were conducted, and computerized tomography was carried out to measure the CCS in 13 patients diagnosed with NPHPT and 16 controls.

Results: There was no association between NPHPT and altered CCS (odds ratio [OR]: 0.27; 95\% confidence interval $[\mathrm{CI}]: 0.05-1.26 ; p=0.095)$. Differences between the case and control groups were found in terms of body mass index (BMI) $\left(26.97 \mathrm{~kg} / \mathrm{m}^{2} \mathrm{vs} 31.53 \mathrm{~kg} / \mathrm{m}^{2}\right.$, respectively; $p=0.044)$, HbA1c (5.59\% vs 6.62\%; $p=0.000)$, and TC $(188.07 \mathrm{mg} / \mathrm{dL}$ vs $220.64 \mathrm{mg} / \mathrm{dL}$; $p=0.088$ ). After adjustment for potential confounders, no statistical significance was observed for the association between changes in CCS and presence of NPHPT (adjusted OR: 1.64; 95\% CI: $0.1-26.43 ; p=0.726$ ).

Conclusion: No association was found between the CCS and the presence of NPHPT.

Keywords: primary hyperparathyroidism, multidetector computed tomography, coronary calcium score

\section{Introduction}

Primary hyperparathyroidism (PHPT) is a common disorder characterized by incomplete regulation and excessive secretion of parathyroid hormone (PTH) from one or more of the parathyroid glands. ${ }^{1}$ This condition is easily diagnosed by the occurrence of an inappropriately high serum PTH level, along with hypercalcemia. However, normocalcemia in the presence of an increased serum PTH level may be due to normocalcemic primary hyperparathyroidism (NPHPT). In such cases, it is necessary to exclude secondary causes of PTH elevation, such as vitamin D deficiency, renal failure, and use of thiazide diuretic or lithium, among others. ${ }^{1-3}$ NPHPT may not be an indolent disease because a high prevalence of nephrolithiasis has been shown, ${ }^{4}$ and some studies have suggested an increased cardiovascular risk. ${ }^{3-5}$ 
The prevalence of NPHPT is not well defined due to the different exclusion criteria for secondary causes used in studies. A recent population-based research in Italy evaluated the prevalence of NPHPT and reported a rate of $0.58 \%$ in females and $0.44 \%$ in males. ${ }^{6} \mathrm{~A}$ Brazilian study on 156 females from an osteoporosis data bank in an Endocrinology and Bone Metabolism reference center found 14 patients with NPHPT, representing a prevalence of $8.9 \%$ of the population studied. ${ }^{7}$

An increase in cardiovascular morbidity and mortality is described in classic symptomatic PHPT. ${ }^{8}$ However, this remains controversial in mild disease, in which the serum calcium level is increased to $1 \mathrm{mg} / \mathrm{dL}$ of the upper limit of normal, ${ }^{9}$ although there is evidence of more subtle cardiovascular changes, such as increased vascular stiffness, among others. ${ }^{8}$

Because the diagnosis of PHPT has been previously given with more subtle clinical findings, the investigation of cardiovascular manifestations of the disease has recently turned to less obvious clinical abnormalities. ${ }^{8,10}$ The coronary calcium score (CCS) is a quantitative index of the total coronary artery calcium detected by a computed tomography (CT) scan without the use of contrast media. ${ }^{11} \mathrm{~A}$ high CCS indicates an increased cardiovascular risk in both young and elderly individuals, with a high positive predictive value for cardiovascular disease in all age groups. ${ }^{12}$

According to the Fourth International Workshop on Asymptomatic PHPT, there is a lack of prospective data on cardiovascular outcomes in asymptomatic PHPT. Moreover, the data on the extent and nature of cardiovascular involvement in patients with mild disease are limited. The carotid seems to be more affected than the heart. Routine cardiovascular analysis of these patients is still not recommended and therefore should not be considered in the decision for surgical treatment. ${ }^{13}$

\section{Study population and methods}

Thirteen female NPHPT patients with no preexisting clinical coronary artery disease (CAD) and a control group of 16 females matched for age were evaluated. NPHPT was defined as a serum PTH level above the upper limit of normal, with a normal albumin-adjusted serum calcium level, excluding the following: disorders associated with secondary hyperparathyroidism such as kidney failure (glomerular filtration rate $[\mathrm{GFR}]<60 \mathrm{~mL} / \mathrm{min}$ ) and vitamin D deficiency (serum $25-\mathrm{OH}$ vitamin $\mathrm{D}<20 \mathrm{ng} / \mathrm{mL}$, use of thiazide diuretic or lithium, and presence of gastrointestinal disorders associated with calcium malabsorption.
The study protocol was approved by the ethics in research committee of the University of Pernambuco. All patients provided written informed consent.

The blood pressure (BP) of the patients was measured using an Omron HEM-742INT monitor. The measurements were carried out according to the guidelines and recommendations of the European Society of Hypertension and the European Society of Cardiology. ${ }^{14}$

Dry biochemical analysis (Johnson \& Johnson) was carried out after $12 \mathrm{~h}$ of fasting, and the glycated hemoglobin (HbAlc) concentrations were determined by using a turbidimetric immunoassay (Roche Diagnostics). The serum PTH levels were measured by immunochemiluminescence (Architect; Abbott), and the serum 25-OH vitamin D levels were measured by competitive electrochemiluminescence immunoassay (Liaison; DiaSorin), with inter- and intra-assay coefficients of variation of $8 \%-15 \%$ and $8 \%-13 \%$, respectively; the limit of detection was $2 \mathrm{ng} / \mathrm{mL} .{ }^{15}$

The Agatston calcium score was determined from the product of the total area of calcium derived by a factor of maximum density. ${ }^{16-18}$ A Philips Brilliance CT scanner with 10 channels was used to measure the coronary calcification area. It was divided into the following: $\mathrm{CCS}=0$; negative, which indicates a low probability of $\mathrm{CAD}$ and future cardiovascular events; and altered CCS, with value $\geq 0 . .^{16-18}$

\section{Statistical analysis}

The categorical data were expressed as absolute and relative frequencies and presented in frequency tables. The numerical data were summarized as mean values and standard deviations. In comparing the clinical characteristics between different groups of patients with normal and abnormal CCS values, Pearson's chi-square test was applied when the independent variable was categorical, and Student's $t$-test when the variable was quantitative. The presence of an association between the CCS and the clinical and laboratory variables was estimated by using the prevalence ratios, along with their confidence intervals; the association was adjusted for possible confounders by multivariate logistic regression. The level of significance in the analysis of associations was set at $5 \%(p<0.05)$.

\section{Results}

Of the 13 patients with NPHPT, $4(30.77 \%)$ had a CCS value $>0$, as described below.

The first case was a 66-year-old hypertensive patient with a body mass index (BMI) of $31.71 \mathrm{~kg} / \mathrm{m}^{2}$, abdominal circumference $(\mathrm{AC})$ of $94 \mathrm{~cm}$, serum $25-\mathrm{OH}$ vitamin $\mathrm{D}$ of 
$44 \mathrm{ng} / \mathrm{mL}$, and PTH of $93 \mathrm{pg} / \mathrm{mL}$, with a family history of early CAD and a CCS of 273.

The second case, a 65-year-old hypertensive patient, had a BMI of $35.17 \mathrm{~kg} / \mathrm{m}^{2}$, AC of $104 \mathrm{~cm}$, serum 25-OH vitamin D of $34.4 \mathrm{ng} / \mathrm{mL}$, and PTH of $92 \mathrm{pg} / \mathrm{mL}$. The patient was taking vitamin D and calcium supplements, was on statin therapy, and had a family history of early CAD; the CCS was 41.4.

The third case was a 68-year-old diabetic and hypertensive patient with a BMI of $24.03 \mathrm{~kg} / \mathrm{m}^{2}$, AC of $84 \mathrm{~cm}$, serum 25-OH vitamin D of $25.2 \mathrm{ng} / \mathrm{mL}$, and PTH of $192 \mathrm{pg} / \mathrm{mL}$; this patient was on statin therapy and had a CCS of 309.8 .

The fourth case was 71 years old, with a BMI of $26.03 \mathrm{~kg} /$ $\mathrm{m}^{2}, \mathrm{AC}$ of $86 \mathrm{~cm}$, serum $25-\mathrm{OH}$ vitamin D of $21 \mathrm{ng} / \mathrm{mL}$, and PTH of $103 \mathrm{pg} / \mathrm{mL}$; the patient was on statin and had a CCS of 30.

The patients with NPHPT had an average age of $65( \pm 7.71)$ years, similarly to the members of the control group, whose average age was $61( \pm 7.65)$ years $(p=0.165)$. A statistically significant difference in BMI $\left(26.97 \mathrm{~kg} / \mathrm{m}^{2}\right.$ vs $31.53 \mathrm{~kg} / \mathrm{m}^{2}$, respectively; $p=0.044$ ) was found between the groups.

Regarding the laboratory findings, differences between the groups were observed in the levels of fasting plasma glucose $(92 \pm 13.68 \mathrm{mg} / \mathrm{dL}$ vs $102.58 \pm 14.66 \mathrm{mg} / \mathrm{dL}$, respectively; $p=0.056), \mathrm{HbA} 1 \mathrm{c}(5.59 \pm 0.34 \%$ vs $6.62 \pm 0.58 \%$, respectively; $p=0.000)$, and total cholesterol (TC) $(188.07 \pm 32.99 \mathrm{mg} / \mathrm{dL}$ vs $220.64 \pm 59.14 \mathrm{mg} / \mathrm{dL}$, respectively; $p=0.088$ ).

A significant difference in the diagnosis of diabetes mellitus was observed between the groups, with only 1 (7.69\%) patient among the cases having such diagnosis compared with $6(37.5 \%)$ in the control group $(p=0.062)$. There was also a significant difference in vitamin D supplementation between the groups $(53.85 \%$ vs $12.5 \%$, respectively; $p=0.017$ ) (Table 1).

In the control group, $10(62.5 \%)$ patients were found to have altered CCS. The initial analysis showed no association between presence of NPHPT and altered CCS (odds

Table I Baseline characteristics of study parameters

\begin{tabular}{|c|c|c|c|}
\hline Covariates & NPHPT & Controls & $p$-value \\
\hline Age, years, mean $\pm S D$ & $65.15 \pm 7.71$ & $61.06 \pm 7.65$ & 0.165 \\
\hline Body mass index, $\mathrm{kg} / \mathrm{m}^{2}$, mean $\pm \mathrm{SD}$ & $26.97 \pm 5.14$ & $31.53 \pm 6.25$ & 0.044 \\
\hline Abdominal circumference, $\mathrm{cm}$, mean $\pm \mathrm{SD}$ & $93.84 \pm 11.15$ & $100.93 \pm 12.97$ & 0.131 \\
\hline Glycemia, mg/dL, mean \pm SD & $92 \pm 13.68$ & $102.58 \pm 14.66$ & 0.056 \\
\hline Glycated hemoglobin, $\%$, mean \pm SD & $5.59 \pm 0.34$ & $6.62 \pm 0.58$ & 0.000 \\
\hline Altered blood pressure, $\mathrm{mmHg}, \mathrm{n}(\%)$ & $8(61.54)$ & II (68.75) & 0.684 \\
\hline Total cholesterol, $\mathrm{mg} / \mathrm{dL}$, mean $\pm \mathrm{SD}$ & $188.07 \pm 32.99$ & $220.64 \pm 59.14$ & 0.088 \\
\hline HDL-cholesterol, mg/dL, mean \pm SD & $50.38 \pm 15.46$ & $49.45 \pm 12.60$ & 0.860 \\
\hline LDL-cholesterol, $\mathrm{mg} / \mathrm{dL}$, mean $\pm \mathrm{SD}$ & $109.56 \pm 32.4$ & $134.73 \pm 53.07$ & 0.146 \\
\hline Triglycerides, $\mathrm{mg} / \mathrm{dL}$, median $(\mathrm{P} 25-\mathrm{P} 75)^{* *}$ & $146(1 \mid 4-156)$ & 152.49 (| | 2.34-237.15) & 0.219 \\
\hline Corrected calcium, $\mathrm{mg} / \mathrm{dL}$, mean $\pm \mathrm{SD} *$ & $9.28 \pm 1.05$ & $8.28 \pm 0.45$ & 0.002 \\
\hline Glomerular filtration rate, $\mathrm{mL} / \mathrm{min}$, mean $\pm \mathrm{SD}$ & $89.87 \pm 19.66$ & $98.88 \pm 20.66$ & 0.243 \\
\hline $25-\mathrm{OH}$ vitamin $\mathrm{D}, \mathrm{ng} / \mathrm{mL}$, mean $\pm \mathrm{SD}$ & $35.32 \pm 8.42$ & $26.11 \pm 8.94$ & 0.008 \\
\hline $\mathrm{PTH}, \mathrm{pg} / \mathrm{mL}$, mean $\pm \mathrm{SD}$ & $100.58 \pm 29.83$ & $30.26 \pm 12.00$ & 0.000 \\
\hline Comorbidities, n (\%) & II (84.62) & $15(93.75)$ & 0.422 \\
\hline Smoking, n (\%) & 0 & $2(12.5 \%)$ & 0.186 \\
\hline Family history of early CAD, $n(\%)$ & $2(15.38)$ & 0 & 0.104 \\
\hline Dyslipidemia, n (\%) & $9(69.23)$ & $13(81.25)$ & 0.452 \\
\hline Hypertension, n (\%) & $8(6 \mid .54)$ & II (68.75) & 0.684 \\
\hline Diabetes mellitus, $\mathrm{n}(\%)$ & I (7.69) & $6(37.5)$ & 0.062 \\
\hline \multicolumn{4}{|l|}{ Medications } \\
\hline Vitamin D replacements, $\mathrm{n}(\%)$ & $7(53.85)$ & $2(12.5)$ & 0.017 \\
\hline Calcium replacement, n (\%) & I (7.69) & 0 & 0.259 \\
\hline Bisphosphonate, n (\%) & $2(15.38)$ & 0 & 0.104 \\
\hline Oral hypoglycemic, n (\%) & 0 & $6(37.5)$ & 0.013 \\
\hline Insulin, n (\%) & 0 & I (6.25) & 0.359 \\
\hline Statin, n (\%) & $7(53.85)$ & $6(46.15)$ & 0.379 \\
\hline Angiotensin-converting enzyme inhibitor, $n$ (\%) & $3(23.08)$ & $4(25)$ & 0.904 \\
\hline Angiotensin receptor blocker, $\mathrm{n}(\%)$ & $4(36.36)$ & $7(63.64)$ & 0.513 \\
\hline Calcium channel blocker, $\mathrm{n}(\%)$ & $2(15.38)$ & $3(18.75)$ & 0.811 \\
\hline Platelet antiaggregant, $\mathrm{n}(\%)$ & $2(15.38)$ & 0 & 0.104 \\
\hline
\end{tabular}

Notes: *Mean \pm SD: Student's $t$-test; **Kruskal-Wallis test. Median, P50.

Abbreviations: CAD, coronary artery disease; HDL, high-density lipoprotein; LDL, low-density lipoprotein; NPHPT, normocalcemic primary hyperparathyroidism; P25/P50/P75, 25th, 50th, and 75th percentiles, respectively; PTH, parathyroid hormone; SD, standard deviation. 
ratio [OR]: 0.27; 95\% confidence interval [CI]: 0.05-1.26; $p=0.095$ ) (Table 2).

After adjusting for the covariates such as BMI, $\mathrm{HbAlc}$, and TC levels, and possible confounding factors in the association between NPHPT and altered CCS, no significant difference was found in the case group with altered CCS (adjusted OR: 1.64; 95\% CI: 0.1-26.43; $p=0.726$ ) (Table 3).

\section{Discussion}

This study investigated the role of CCS in patients with NPHPT. No previous research has specifically investigated this association. In fact, the clinical conditions of NPHPT are not yet well characterized, and prospective data on the cardiovascular risk in this group of patients are lacking. In the current work, we measured the CCS, which has been recognized as a good predictor of cardiovascular disease in asymptomatic patients. ${ }^{19}$

The initial analysis showed no association between CCS $>0$ and diagnosis of NPHPT (OR: 0.27; 95\% CI: 0.05-1.26; $p=0.095$ ). By using a similar protocol but in a different population, Kepez et $\mathrm{al}^{9}$ evaluated 31 patients with mild PHPT, which was defined as an increase in serum calcium level of up to $1 \mathrm{mg} / \mathrm{dL}$ above the upper limit of normal, compared with 19 controls; the CCS of the patients was measured by using CT. The authors did not find a positive association between asymptomatic PHPT and coronary calcification. ${ }^{9}$

A population-based study that evaluated metabolic abnormalities in 30 patients with NPHPT compared with 30

Table 2 Association between coronary calcium score and NPHPT

\begin{tabular}{lllll}
\hline Factor & $\mathbf{n}(\%)$ & OR $(\mathbf{9 5 \%} \mathbf{~ C l})$ & p-value \\
\cline { 2 - 3 } & $\mathbf{C C S ~}>\mathbf{0}$ & $\mathbf{C C S ~}=0$ & \\
\hline NPHPT & & & & \\
No & $10(62.5)$ & $6(37.5)$ & Reference & NA \\
Yes & $4(30.77)$ & $9(69.23)$ & $0.27(0.05-1.26)$ & 0.095 \\
Total & $14(48.28)$ & $15(51.72)$ & NA & NA \\
\hline
\end{tabular}

Abbreviations: $\mathrm{CCS}$, coronary calcium score; $\mathrm{Cl}$, confidence interval; NPHPT, normocalcemic primary hyperparathyroidism; NA, not available; OR, odds ratio; PTH, parathyroid hormone.

Table 3 Association between coronary calcium score and the condition of NPHPT adjusted for potential confounders*

\begin{tabular}{lllll}
\hline Calcium score & OR & p-value & OR $_{\text {adjusted }}$ & p-value \\
\hline NPHPT & & & & \\
No & Reference & NA & Reference & NA \\
Yes & 0.27 & 0.096 & $1.64(0.1-26.43)$ & 0.726 \\
\hline
\end{tabular}

Note: *Adjusted for covariates such as body mass index, glycated hemoglobin, and total cholesterol.

Abbreviations: NA, not available; NPHPT, normocalcemic primary hyperparathyroidism; OR, odds ratio. controls found significantly higher levels of blood glucose and triglycerides, as well as a higher mean BMI and lower high-density lipoprotein (HDL) cholesterol levels, in the group with increased PTH, suggesting metabolic changes in NPHPT associated with cardiovascular risk. ${ }^{20}$

In the current study, however, more metabolic changes were observed in the control group, and although the groups were matched for age, the control group had a significantly higher mean BMI $\left(31.53 \mathrm{~kg} / \mathrm{m}^{2}\right.$ vs $\left.26.97 \mathrm{~kg} / \mathrm{m}^{2} ; p=0.044\right)$ and mean HbA1c level $(6.62 \%$ vs $5.59 \% ; p=0.000)$ and showed a trend toward higher mean fasting plasma glucose $(102.58 \mathrm{mg} / \mathrm{dL}$ vs $92 \mathrm{mg} / \mathrm{dL} ; p=0.056)$ and TC $(220.64 \mathrm{mg} / \mathrm{dL}$ vs $188.07 \mathrm{mg} / \mathrm{dL} ; p=0.088)$ levels. In addition to the differences in clinical and laboratory results, the diagnosis of diabetes mellitus also differed between the groups, with only $1(7.69 \%)$ patient having such diagnosis in the case group compared with $6(37.5 \%)$ in the control group $(p=0.062)$, findings which may have been potential confounders.

The current work found no difference between the case and control groups in either the diagnosis of hypertension or changes in BP levels. In contrast, a recent retrospective study that compared the systolic and diastolic BP levels between a group of 11 patients with NPHPT and 296 control patients found that patients with high PTH and normal calcium levels had higher BP levels than those without NPHPT. ${ }^{21}$ The results of the current study may have been influenced by the fact that the control group had a higher BMI than the case group, given that it is well established in the literature that hypertension is correlated with excess weight. ${ }^{22}$

\section{Strength vs limitations}

This is the first study to verify the association between NPHPT and changes in CCS. However, this research had a small sample size, and the control group had higher rates of known cardiovascular risk factors.

\section{Conclusion}

No association was found between the CCS and NPHPT.

\section{Disclosure}

The authors report no conflicts of interest in this work.

\section{References}

1. Bilezikian JP, Silverberg SJ. Normocalcemic primary hyperparathyroidism. Arq Bras Endocrinol Metabol. 2010;54(2):106-109.

2. Eufrasino CS, Holanda NC, Prazeres PA, Bandeira F. Epidemiology of primary hyperparathyroidism and its nonclassical manifestations in the city of Recife, Brazil. Clin Med Insights Endocrinol Diabetes. 2013;6:69-74. 
3. Bandeira F, Griz L, Chaves N, et al. Diagnosis and management of primary hyperparathyroidism - a scientific statement from the Department of Bone Metabolism, the Brazilian Society for Endocrinology and Metabolism. Arq Bras Endocrinol Metabol. 2013;57(6): 406-424.

4. Amaral LMB, Queiroz DC, Marques TF, Mendes M, Bandeira F. Normocalcemic versus hypercalcemic primary hyperparathyroidism: more stone than bone? J Osteoporos. 2012;2012:128352.

5. Díaz-Soto G, Julián MT, Puig-Domingo M. Normocalcemic primary hyperparathyroidism: a newly emerging disease needing therapeutic intervention. Hormones. 2012;11(4):390-396.

6. Vignali E, Cetani F, Chiavistelli S, et al. Normocalcemic primary hyperparathyroidism: a survey in a small village of Southern Italy. Endocr Connect. 2015;4(3):172-178.

7. Marques TF, Vasconcelos R, Diniz E, Rêgo D, Griz L, Bandeira F. Normocalcemic primary hyperparathyroidism in clinical practice: an indolent condition or a silent threat? Arq Bras Endocrinol Metabol. 2011;55(5):314-317.

8. Walker MD, Rubin M, Silverberg SJ. Non-traditional manifestations of primary hyperparathyroidism. J Clin Densitom. 2013;16(1):40-47.

9. Kepez A, Harmanci A, Hazirolan T, et al. Evaluation of subclinical coronary atherosclerosis in mild asymptomatic primary hyperparathyroidism patients. Int J Cardiovasc Imaging. 2009;25(2):187-193.

10. Walker MD, Fleischer J, Rundek T, et al. Carotid vascular abnormalities in primary hyperparathyroidism. J Clin Endocrinol Metab. 2009;94(10):3849-3856.

11. McClelland RL, Jorgensen NW, Budoff M, et al. 10-year coronary heart disease risk prediction using coronary artery calcium and traditional risk factors. Derivation in the MESA (multi-ethnic study of atherosclerosis) with validation in the HNR (Heinz Nixdorf Recall) study and the DHS (Dallas Heart Study). J Am Coll Cardiol. 2015;66(15): 1643-1653.

12. Tota-Maharaj R, Blaha MJ, Blankstein R, et al. Association of coronary artery calcium and coronary heart disease events in young and elderly participants in the multi-ethnic study of atherosclerosis: a secondary analysis of a prospective, population-based cohort. Mayo Clin Proc. 2014;89(10):1350-1359.
13. Silverberg SJ, Clarke BL, Peacock M, et al. Current issues in the presentation of asymptomatic primary hyperparathyroidism: Proceedings of the Fourth International Workshop. J Clin Endocrinol Metab. 2014;99(10):3580-3594.

14. Mancia G, Fagard R, Narkiewicz K, et al. 2013 ESH/ESC guidelines for the management of arterial hypertension: the Task Force for the management of arterial hypertension of the European Society of Hypertension (ESH) and of the European Society of Cardiology (ESC). J Hypertens. 2013;31(7):1281-1357.

15. Ersfeld DL, Rao DS, Body JJ, et al. Analytical and clinical validation of the $25 \mathrm{OH}$ vitamin D assay for the LIASON automated analyser. Clin Biochem. 2004;37(10):867-874.

16. Shabestari AA. Coronary artery calcium score: a review. Iran Red Crescent Med J. 2013;15(12):e16616.

17. Detrano R, Guerci AD, Carr JJ, et al. Coronary calcium as a predictor of coronary events in four racial or ethnic groups. $N$ Engl J Med. 2008;358(13):1336-1345.

18. Greenland P, Alpert JS, Beller GA, et al. American College of Cardiology Foundation/American Heart Association Task Force on practice guidelines. Foundation/American Heart Association Task Force on practice guidelines adults: executive summary: a report of the American College of Cardiology 2010 ACCF/AHA Guideline for Assessment of Cardiovascular Risk in Asymptomatic. Circulation. 2010;122:2748-2764.

19. Dikic M, Tesic M, Markovic Z, et al. Prognostic value of calcium score and coronary flow velocity reserve in asymptomatic diabetic patients. Cardiovasc Ultrasound. 2015;13:41.

20. Hagström E, Lundgren E, Rastad J, Hellman P. Metabolic abnormalities in patients with normocalcemic hyperparathyroidism detected at a population-based screening. Eur J Endocrinol. 2006;155(1):33-39.

21. Chen G, Xue Y, Zhang Q, et al. Is normocalcemic primary hyperparathyroidism harmful or harmless? J Clin Endocrinol Metab. 2015;100(6):2420-2424.

22. Stone NJ, Robinson JG, Lichtenstein AH, et al. 2013 ACC/AHA guideline on the treatment of blood cholesterol to reduce atherosclerotic cardiovascular risk in adults: a report of the American College of Cardiology/American Heart Association Task Force on Practice Guidelines. J Am Coll Cardiol. 2014;63(25 pt B):2889.
Vascular Health and Risk Management

\section{Publish your work in this journal}

Vascular Health and Risk Management is an international, peerreviewed journal of therapeutics and risk management, focusing on concise rapid reporting of clinical studies on the processes involved in the maintenance of vascular health; the monitoring, prevention and treatment of vascular disease and its sequelae; and the involvement of

\section{Dovepress}

metabolic disorders, particularly diabetes. This journal is indexed on PubMed Central and MedLine. The manuscript management system is completely online and includes a very quick and fair peer-review system, which is all easy to use. Visit http://www.dovepress.com/ testimonials.php to read real quotes from published authors. 